800,000 the figures are several times less. Thus, for natural rubber $M \mathrm{st}=193,000$ instead of 830,000 , but for synthetic rubber $M_{\mathrm{St}}=$
68,000 instead of 73,000 . This result is in good agreement with data in the literature.

One can compute, on a model of an elongated ellipsoid, the length $l=2 b$ of the particles from the values of $M$ and $b / a$. For natural rubber we obtain in this way $l=3500 \mathrm{~A}$., whereas from the depolarization of diffuse light $l$ was found to be $3400 \mathrm{~A}$. for the same system $(0.1 \text { per cent solution of natural rubber in carbon tetrachloride })^{7}$. Thus it appears that Polson's method can be applied to linear polymers over a wider range than might have been theoretically presumed.

All the rubber samples studied are characterized by an appreciable excess of the maximal ordinate of the normalized experimental diffusion curve over the ideal curve (this appears also from Fig. 1), thereby indicating polydispersity of these substances. Gralén $n^{8}$ suggested a convenient method of quantitative estimation of polydispersity as convenient method of quantitative estimation of polydispersity as
characterized by the ratio of the diffusion coefficients $D_{2} / D_{1}$ computed characterized by the ratio of the diffusion coefficients $D_{2} / D_{1}$ computed
from the standard deviation and from the maximal ordinate of the from the standard deviation and from the maximal ordinate of the
diffusion curve. For a monodisperse substance, $D_{2}=D_{1}$ or $D_{2} / D_{1}=1$; diffusion curve. For a monodisperse substance, $D_{2}=D_{1}$ or $D_{2} / D_{1}=1$;
for natural rubber we have found $D_{2} / D=1 \cdot 17$, after a twofold precipitation $D_{2} / D_{1}=1 \cdot 18$, after thermal destruction $D_{2} / D_{1}=1 \cdot 72$, etc. cipitation $D_{2} / D_{1}=1 \cdot 18$, after thermal destruction $D_{2} / D_{1}=1 \cdot 72$, etc.
Assuming the logarithmic course of the distribution curve, one can, after Gralén, calculate from $D_{2} D_{1}$ complete distribution curves (Fig. 2 ), and thus obtain a more demonstrative picture of polydispersity of the substance. Finally, it can be shown that in the general equation the substance. Finally, it can be shown that in the general equation for asymmetrical particles, $M=-K / D^{\alpha}$, the value of $a$ for natural it follows that for linear polymers the change of $D$ follows very closely the change in the molecular weight.

on the whole, the application of the above methods to the rubberlike polymers enables one to obtain from the diffusion and viscosity measurements a fairly complete molecular characterization of these substances. This is particularly signiflcant for laboratories which do not possess an ultracentrifuge.

A full account of this work will be published in the near future in Acta physicochim. USSR.

Laboratory of Colloid Chemistry, A. G. PaSSYNSKY.
T. V. GATOVSKASA.

Karpov Institute of Physical Chemistry, Moscow.

${ }^{1}$ Lamm, O., Nowa Acta Reg. Soc. Scient. Uppsal., 10, No. 6 (1937). Simha, R., J. Phys. Chem., 44, 25 (1940). Mehl, J., Oncley, J., and Simha, R., Science, 92, 131 (1940).

'Campbell, H., and Johnson, P., Trans. Farad. Soc., 40, 221 (1944). "Frenkel, I., Acta Physicochim., 19, 51 (1944).

Polson, A., Koll. Z., 88, 51 (1939).

in Davis and Blake, "The Chemistry and Technology of Rubber" (1937), 232.

7 Gehmann and Field, Ind. Eng. Chem., 29, 793 (1937)

${ }^{8}$ Gralén, N., Koll. Z., 95, 188 (1941).

\section{Mechanism of the Beckmann Rearrangement}

THE recent resurgence of interest in the mechanism of the Beckmann change reffects the perennial fascination which this subject has for chemists. First, Higman ${ }^{2}$ and LeFevre ${ }^{2}$ have suggested that the cation (I) rearranges by rotation of the central pair $>\mathrm{C}=\mathrm{N}<$ through $90^{\circ}$ to form (II).<smiles>[R2]C([R2])=[NH+]O</smiles>

(i)<smiles>[R][NH+]=C([R2])O</smiles>

(II)
Such a mechanism, as Dewar ${ }^{3}$ has pointed out, is completely at variance with the data obtained from careful studies of the rearrangements of the picryl ethers and the benzene sulphonyl esters of ketoximes 4 Secondly, Brodsky and Micluchin ${ }^{5}$, in some recently available publications, have questioned the correctness of the usually accepted view of the intramolecular nature of the transformation because the benzanilide formed by the addition of water, containing an excess of the heavy isotope $0^{18}$, to the product resulting from the rearrangement of benzophenone oxime by phosphorus pentachloride itself contained $0^{18}$. In any formulation of the mechanism of the Beckmann rearrangeIn any formulation of the mechanism of the Beckmann rearrange-
ment, it has to be remembered that the change involves the migration of two radicals: $(a)$ the hydrocarbon radical $R$ from carbon to nitrogen, and $(b)$ the $0 \mathrm{H}$ or ()$X$ group from nitrogen to carbon. nitrogen, and ( $b$ ) the $O H$ or $O X$ group from nitrogen to carbon. Campbell and Kenyon's elegant demonstration
resulting from the rearrangement of the oxime of $(4)-\alpha$-phenylethylresulting from the rearrangement of the oxime of $(4)-\alpha$-phenylethylcule by an asymmetric carbon atom, possesses $99 \cdot 6$ per cent of the activity of optically pure $(-)$-aceto- $a$-phenylethylamine relates to activity of optically pure ( - )-aceto- $\alpha$-phenylethylamine relates to
process $(a)$ only, but it proves conclusively that the asymmetric process $(a)$ only, but it proves conclusively that the asymmetric migrating group is never kinetically free: electron-sharing between the rearrangement. With regard to process $(b)$, there is as yet no
the clear-cut evidence as to the mode of transit of $O X$ from nitrogen to carbon ; this may occur by an intramolecular route or by dissociation into free ions. Although the data are well interpreted by an intramolecular migration, there is in the picryl ethers and benzene sulphonyl esters no reason to object to the mechanism:

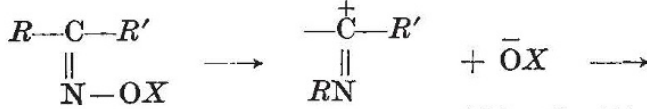

$$
\begin{aligned}
& \mathrm{XO}-\underset{\|}{\mathrm{C}}-R^{\prime} \longrightarrow \text { amide }
\end{aligned}
$$

nor for the rearrangement by an acid reagent to

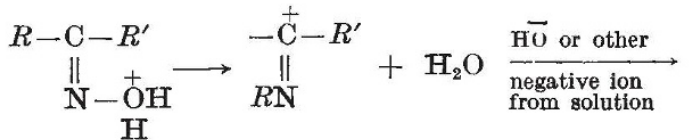

$$
\begin{aligned}
& \underset{R-\mathrm{N}}{\mathrm{HO}-\mathrm{C}-R^{\prime}} \rightarrow \underset{R \mathrm{NH}}{\mathrm{OC} R^{\prime}}
\end{aligned}
$$

Indeed, Chapman ${ }^{7}$ has found that when a mixture of the homopicryl (that is, $2: 4: 6$-trinitro- $m$-cresyl) ether of benzophenone oxime and the picryl ether of the oxime of di- $p$-tolylketone undergoes rearrange$p$-toluidide, $p$-Me. ${ }_{6} \mathrm{H}_{4} \cdot \mathrm{CO} . \mathrm{N}\left\langle\begin{array}{l}\mathrm{C}_{6} \mathrm{H}\left(\mathrm{NO}_{3}\right)_{3} \cdot \mathrm{Me} \\ \mathrm{C}_{6} \mathrm{H}_{4} \cdot \mathrm{Me}(p)\end{array}\right.$ This may arise as the result of the ionization of $O X$ but, on the other hand, it may conceivably be the consequence of exchange in the picryl ethers before rearrangement

If, however, ionization occurs, it must either occur simultaneousiy with, or after migration of, the group $R$. It cannot precede it, otherwise there would not be such a strict stereochemical determination of the products in rearrangements of this kind.

The new evidence of Brodsky and Micluchin, based on the use of the isotope $\mathrm{O}^{18}$, from which it is concluded that the rearrangement is not intramolecular, is open to criticism because of the use of phosphorus pentachloride. Although its function in the Beckmann rearrangement similar to that on other hydroxy compounds, namely:

$$
R \mathrm{OH}+\mathrm{PCl}_{5} \rightarrow R O . \mathrm{PCl}_{4}+\mathrm{HCl} \rightarrow R \mathrm{Cl}+\mathrm{POCl}_{3}+\mathrm{HCl} \text {. }
$$

If this be so, then its role in the rearrangement of a ketoxime may be formulated as follows:

$$
\underset{\substack{\mathrm{N}-\mathrm{OH}}}{\|}+\mathrm{PCl}_{5} \longrightarrow \mathrm{HCl}+\underbrace{\|}_{\text {an ester of strong acid }}
$$

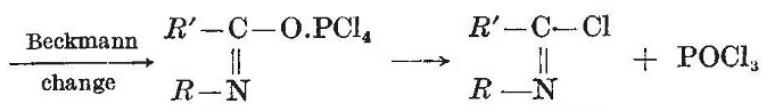
(V)

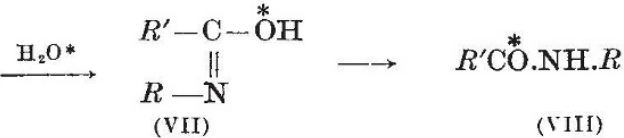

Compound (V) on decomposition can give rise to an oxygen-free compound (VI), which will inevitably yield with water enriched with the heavy isotope $\mathrm{O}^{18}$ an amide (VIII) containing $0^{18}$. It is therefor clear that although process $(b)$ may well prove in fact to be an inter molecular process, the new data of Brodsky and Micluchin do not by themselves disprove an intramolecular mechanism of the transformaion.

From the combined data at present available, it may be concluded that the Beckmann change involves: $(a)$ an intramolecular migration of the hydrocarbon radical $R$ from carbon to nitrogen, and $(b)$ a sim ultaneous or subsequent transfer of the group $O X$ to the carbon atom (with the eventual formation of the amide) which is possibly intermolecular in character.

Chemistry Department,

BRYNMOR JONES.

University, She

1 Higman, Nature, 156, 242 (1945)

LeFevre, $J$. Soc. Chem. Ind., 49, 391 (1945).

Dewar, Nature, 156, 688 (1945).

For summary and references, see Brynmor Jones, Chem. Rev., 85, 335 (1945).

${ }^{5}$ Brodsky and Micluchin, C.R. Acad. Sci. U.S.S.R., 32, 558 (1941). J. Chem. Phys., 11, 342 (1943).

- Campbell and Kenyon, J. Soc. Chem. Ind., 49, 391 (1945), and private communication.

$\checkmark$ Chapman. private communication. 